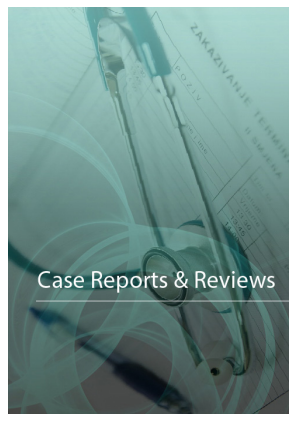

Correspondence

Kinal Bhatt

Division of Clinical \& Translational Research, Larkin Health System, South Miami, FL, USA

Tel: +1 (928) 2250273

E-mail: kinalbhatt@gmail.com

- Received Date: 08 Oct 2020

- Accepted Date: 23 Oct 2020

- Publication Date: 06 Nov 2020

\section{Copyright}

() 2020 Science Excel. This is an openaccess article distributed under the terms of the Creative Commons Attribution 4.0 International license.

\title{
Burdening of healthcare system by expected second wave of COVID-19 with influenza co-infection
}

\author{
Kinal Bhatt* and Marcos Sanchez-Gonzalez \\ Division of Clinical \& Translational Research, Larkin Health System, South Miami, FL, USA
}

Coronavirus disease 2019 (COVID-19) is a novel virus caused by severe acute respiratory syndrome coronavirus 2 (SARS-COV-2), which originated from China in late December of 2019, now spread globally and continues to raise death toll [1]. While the world is struggling with COVID-19 devastation to healthcare system and economy, many parts of the globe face the prospect of COVID-19 pandemic and a simultaneous seasonal influenza epidemic. Both flu and COVID-19 may be asymptomatic or have mild to severe symptoms. Some of the common symptoms both COVID-19 and flue share include: fever or chills, cough, shortness of breath or difficulty breathing, fatigue (tiredness), sore throat, runny or stuff nose, muscle pain or body aches, headache, and rarely diarrhea in children and adults [2]. A person infected with flu may develop symptoms anywhere from 1 to 4 days post-infection and may be contagious up to 3-7 days. A 2-15 days of incubation period is estimated for COVID-19, however length of how long a patient may stay contagious is currently under investigation (Figure 1) [2]. While there are many epidemiologic similarities between COVID-19 and flu viruses, including person-toperson droplet spread in close contact (within 6 feet distance), COVID-19 is more contagious (spreads more rapidly and easily; "superspreader") in elderly, people with certain underlying medical conditions and pregnant women [2]. Influenza (flu) mainly occurs during the winter season, and 1918 and 1957 influenza pandemics experiences has alerted healthcare community for a possible resurgence of COVID-19 wave in the fall and winter $[3,4]$. While there is much uncertainty about the timing and severity of COVID-19, a few cases of COVID-19 and flu coinfections have been reported from China, Iran, Turkey and the USA [5-7].

A hospital in China [5] reported five out of 115 (incidence rate of 4.35\%) hospitalized COVID-19 patients with COVID19 and flu coinfection and assessed clinical characteristics of them [5]. Three of five patients tested positive for Influenza A Virus (60\%), and the other two cases (40\%) had Influenza B Virus. Two males and three females age ranged from 39 to 66 years, at least $2(60 \%)$ had past medical history of hypertension (HTN), 1 (20\%) reported cardiovascular disease, $2(40 \%)$ reported hepatitis B virus (HBV). Common symptoms among five patients included fever
(100\%), cough (100\%), and shortness of breath $(100 \%)$, myalgia $(40 \%)$, fatigue $(40 \%)$, headache (40\%), chest pain (20\%), nasal tampon (60\%), expectoration (40\%), pharyngalgia (60\%), and hemoptysis (20\%) [5]. Admission labs for five patients were reported as reduced lymphocytes (80\%), liver ALT and AST levels (40\%), C-reactive protein (CRP) (80\%), and increased procalcitonin levels (40\%). All patients were given antiviral therapy, oxygen and antibiotics and stayed in the hospital anywhere from 12 to 30 days without needing intensive care unit, and no death reported. The researchers did not report more severity in coinfection patients based on laboratory findings, imaging studies and patient prognosis. They rather showed similar clinical symptoms as those with COVID-19 infection only; however, nasal tampon and pharyngalgia appear to be more prone for coinfected patients.

A study by Ozaras et al. [7] was published of an academic hospital in Southern Iran of four patients with confirmed COVID19 and Influenza A virus coinfection. Another group of physicians [7] has also discussed a case of a 66 years old African American woman who presented with a syncopal episode, complained of fever, non-productive cough, shortness of breath, and decreased appetite. This patient had many coexisting medical diagnosis thought to increase risk of COVID-19 transmission; ischemic cardiomyopathy, type- 2 diabetes mellitus, hypertension. Coronary artery disease and chronic kidney disease. Despite treatment with supplementary oxygen, antiviral Tamiflu, antibiotics azithromycin and ceftriaxone usage, this patient's dropping oxygen saturation rate subsequently required intubation and ventilation.

Another study in Turkey [7] reported 6 out of 1103 patients $(0.54 \%)$ patients who were confirmed COVID19 and influenza coinfections, mild to moderate in severity. This hospital eventually had reported 28 such cases. The study suggested thoracic imaging was just as important as laboratory findings in differentiating influenza to those of COVID19 infection. Four out of six patients were mild to moderate Influenza B, who did not require ventilator support and improved without complications. The other two patients reported dead were presumed to have Influenza A and were ventilator dependent. Reverse Transcription Polymerase Chain Reaction and viral culture are 


\begin{tabular}{|c|c|c|}
\hline & Influenza & COVID-19 \\
\hline Asymptomatic or symptomatic & $\begin{array}{c}\text { Patients can be asymptomatic } \\
\text { due to herd immunity }\end{array}$ & $\begin{array}{l}\text { Most patients develop } \\
\text { symptoms within } 2 \text { days } \\
\text { of infection }\end{array}$ \\
\hline Viral shedding & 5-10 days & $\begin{array}{l}\text { Up to } 14 \text { days or even } \\
\text { longer }\end{array}$ \\
\hline Severity of illness & $\begin{array}{l}\text { Majority of infections are } \\
\text { mild to moderate }\end{array}$ & Severe illness can occur \\
\hline Mortality & Less than $1 \%$ & $3-4 \%$ \\
\hline Vaccines & $\begin{array}{l}\text { Vaccines available; } \\
\text { efficacy varies from } \\
\text { season to season }\end{array}$ & $\begin{array}{l}\text { No vaccine available, } \\
\text { clinical trials in progress }\end{array}$ \\
\hline Treatment & $\begin{array}{l}\text { Oseltamivir } \\
\text { Zanamivir } \\
\text { Peramivir } \\
\text { Baloxavir }\end{array}$ & $\begin{array}{l}\text { No treatment available, } \\
\text { clinical trials in progress }\end{array}$ \\
\hline $\begin{array}{l}\text { Acute respiratory distress } \\
\text { syndrome }\end{array}$ & Less common & More common \\
\hline
\end{tabular}

Figure 1. Differences between influenza and COVID-19. Note: Reprinted from Konala V. Co-infection with Influenza A and COVID-19. Eur J Case Reports Internal Med. 2020; 7: 001656.

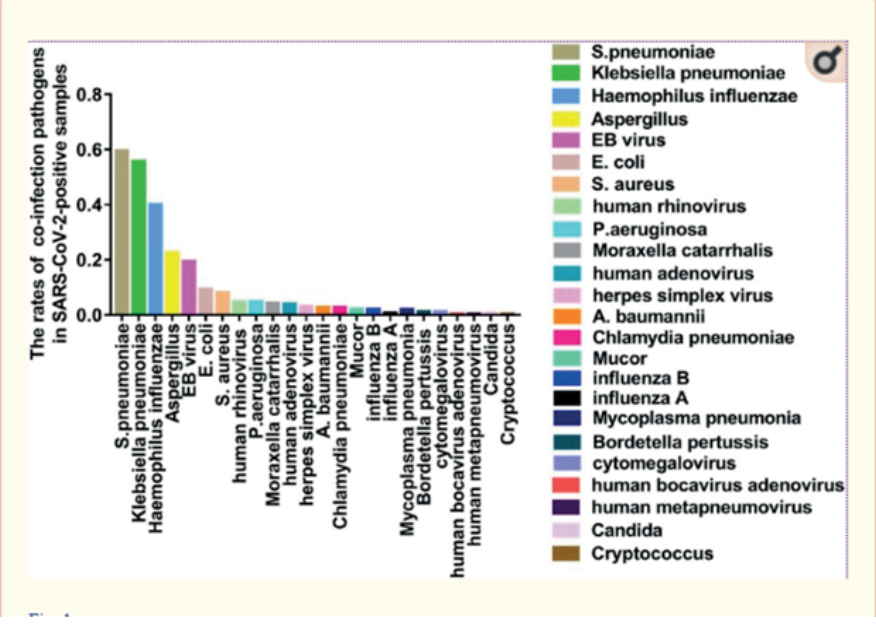

Figure 2. Distribution of respiratory pathogens with SARS-CoV-2 coinfection. Note: Reprinted from $\mathrm{Zhu} X$, Co-infection with respiratory pathogens among COVID-2019 cases. Virus Res. 2020: 285.

highly sensitive and specific tests to detect influenza, however latter takes 3-4 days for results [7]. In this study, researchers had used rapid antigen detection method with DFA assay that has turnaround time of $<30$ minutes, however only $60 \%$ to $80 \%$ sensitivity compared to almost $100 \%$ sensitivity of RT-PCR and viral culture [7].

Wu et al. [8] reported a case of a 69 year old male who tested negative for COVID19 despite having typical symptoms of dry cough and fever and revealed ground glass appearance on CT scan. Patient had tested positive for Influenza A, was discharged home on Oseltamivir and isolation instructions, and subsequently developed Acute Respiratory Distress Syndrome and lymphopenia. Repeat COVID19 nasopharyngeal swab and sputum sample was again tested negative. Patient was intubated, and bronchoalveolar lavage performed revealed positive test for SARS-COV-2.
Zhu et al. [9] conducted a trial of 257 laboratory confirmed COVID-19 patients in Jiangusu province of China between January 22 to February 22, 2020. These patients were re-confirmed by realtime PCR and tested for 39 other respiratory pathogens, including bacteria, fungal and viral pathogens. In total (Figure 2), 242 (94.2\%) patients were co-infected with one or more pathogens, 24 respiratory pathogens discovered, mostly bacterial. While Streptococcus pneumoniae was the most common coinfection pathogen, next followed Klebsiella pneumoniae and Haemophilus influenza, mostly in severe COVID-19 cases occurring 1-4 days of onset of COVID-19 disease. A sum of 22 (8.5\%) patients were asymptomatic, 140 (54.5\%) were moderate cases, 17 (6.6\% were severe/critical cases, and no mortality reported despite 3 critical patients with ICU admissions. The study observed more men (53.7\%) were affected than women, but most female (68.2\%) were asymptomatic. 11 (4.3\%) Pediatric patients (below 15 years of age) were also part of the patient population, however none reported severe or critical.

COVID-19 and Influenza-A infection may be rare, but these numbers are rising across the globe as we approach fall and winter seasons. If physicians are not vigilant and not testing for potential coinfections based on symptoms and geographical areas, we may be underdiagnosing or underestimating other viral coinfections with COVID19 [7]. The expected second wave of COVID19 in September/ October also happens to be start date of influenza season [7]. There is no proven treatment for COVID-19, and coinfection may play a role in immunity suppression $[7,9]$. It is extremely important to recognize coinfections early as treatment requirements may be different. A study by Li et al. [10] demonstrated increasing influenza vaccination rate prior to peak influenza season may have positive impact in patients reporting non-specific symptoms, influenza like illness (ILI). These prevention methods may help prevent further burdening our health care system and reduce ILI symptoms, further reducing COVID19 transmission.

\section{References}

1. Onigbinde SO, Ojo AS, Fleary L, et al. Chest Computed Tomography Findings in COVID-19 and Influenza: A Narrative Review. BioMed Rese Int. 2020: 6928368.

2. Center for Disease Control and Prevention. Similarities and Differences between Flu and COVID-19. 2020. Available from: https://www.cdc.gov/flu/symptoms/flu-vs-covid19.htm

3. Wu D, Lu J, Ma X, et al. Coinfection of Influenza Virus and Severe Acute Respiratory Syndrome Coronavirus 2 (SARSCOV-2). Pediat Iinfect Dise J. 2020; 39: e79.

4. Belongia E, Osterholm M. COVID-19 and flu, a perfect storm. Science. 2020; 368: 1163.

5. Ding Q, Lu P, Fan Y, et al. The clinical characteristics of pneumonia patients coinfected with 2019 novel coronavirus and influenza virus in Wuhan, China. J Med Virol. 2020: 20.

6. Khodamoradi Z, Moghadami M, Lotfi M. Co-infection of Coronavirus Disease 2019 and Influenza A: A Report from Iran. Arch Iran Med. 2020; 23: 239-243.

7. Ozaras R, Cirpin R., Duran A, et al. Influenza and COVID019 coinfection: Report of six cases and review of literature. J Med Virol. 2020: 19.

8. Konala VM, Adapa S, Naramala S, et al. A Case Series of Patients Coinfected With Influenza and COVID-19. J Investiga Med High Impact Case Reports. 2020; 8: 2324709620934674.

9. Zhu $\mathrm{X}, \mathrm{Ge} \mathrm{Y}, \mathrm{Wu}, \mathrm{T}$, et al. Co-infection with respiratory pathogens among COVID-2019 cases. Virus Res. 2020; 285: 198005.

10. Li Q, Tang B, Bragazzi NL, et al. Modeling the impact of mass influenza vaccination and public health interventions on COVID-19 epidemics with limited detection capability. Mathemati Biosci. 2020; 325: 108378. 